ARTICLE

\title{
Catalytic enantioselective reductive domino alkyl arylation of acrylates via nickel/photoredox catalysis
}

Pengcheng Qian ${ }^{1,5}$, Haixing Guan ${ }^{1,2,5}$, Yan-En Wang ${ }^{3}$, Qianqian Lu¹, Fan Zhang ${ }^{1}$, Dan Xiong1, Patrick J. Walsh (i) ${ }^{4 \times} \&$ Jianyou Mao (i) ${ }^{1 \times}$

Nonsteroidal anti-inflammatory drug derivatives (NSAIDs) are an important class of medications. Here we show a visible-light-promoted photoredox/nickel catalyzed approach to construct enantioenriched NSAIDs via a three-component alkyl arylation of acrylates. This reductive cross-electrophile coupling avoids preformed organometallic reagents and replaces stoichiometric metal reductants by an organic reductant (Hantzsch ester). A broad range of functional groups are well-tolerated under mild conditions with high enantioselectivities (up to $93 \%$ ee) and good yields (up to $90 \%$ ). A study of the reaction mechanism, as well as literature precedence, enabled a working reaction mechanism to be presented. Key steps include a reduction of the alkyl bromide to the radical, Giese addition of the alkyl radical to the acrylate and capture of the $\alpha$-carbonyl radical by the enantioenriched nickel catalyst. Reductive elimination from the proposed $\mathrm{Ni}(\mathrm{III})$ intermediate generates the product and forms $\mathrm{Ni}(\mathrm{I})$.

\footnotetext{
${ }^{1}$ Technical Institute of Fluorochemistry (TIF), Institute of Advanced Synthesis, School of Chemistry and Molecular Engineering, Nanjing Tech University, Nanjing, PR China. ${ }^{2}$ Experimental Center, Key Laboratory of Traditional Chinese Medicine Classical Theory, Ministry of Education, Shandong University of Traditional Chinese Medicine, Jinan, PR China. ${ }^{3}$ College of Science, Hebei Agricultural University, Baoding, PR China. ${ }^{4}$ Roy and Diana Vagelos Laboratories, Department of Chemistry, University of Pennsylvania, Philadelphia, PA, USA. ${ }^{5}$ These authors contributed equally: Pengcheng Qian, Haixing Guan.

凶email: pwalsh@sas.upenn.edu; ias_jymao@njtech.edu.cn
} 
E nantioenriched $\alpha$-aryl propionic acids are an important class of nonsteroidal anti-inflammatory medications (NSAIDs) $)^{1,2}$ and are also key building blocks for further elaboration. As a result, significant effort has been devoted to the asymmetric synthesis of $\alpha$-aryl carboxylic acid derivatives. Among enantioselective methods to prepare these structural motifs, asymmetric hydrogenation ${ }^{3,4}$ and hydrocarboxylation ${ }^{5}$ stand out. A more efficient approach to access such tertiary stereocenters, however, would be the transition metal catalyzed asymmetric $\alpha$-arylation of esters.

The asymmetric cross-coupling between $\alpha$-halo esters and organometallic reagents (e.g., Grignard, organozinc, organoboron, and organosilicon) (Fig. 1a) was developed and driven mainly by G.C. Fu and coworkers ${ }^{6-9}$. A complementary approach was reported by Zhou $^{10}$ and Gaunt ${ }^{11}$ involving asymmetric arylation of enol silane derivatives with aryl sulfonates or iodonium salts under enantioselective transition metal catalysis (Fig. 1b). Motivated by a desire to broaden the scope of coupling partners while also avoiding moistureand air-sensitive organometallic reagents, Reisman ${ }^{12-16}$, Doyle ${ }^{17}$, Weix $^{18}$, and their groups developed nickel catalyzed asymmetric reductive cross-electrophile coupling reactions using stoichiometric metal reductants ( $\mathrm{Zn}$ or $\mathrm{Mn}$ ). Inspired by their elegant studies, we disclosed an example of highly enantioselective nickel-photoredox catalyzed reductive cross-coupling of racemic $\alpha$-chloro esters with aryl iodides (Fig. 1c) to construct enantioenriched NSAID derivatives ${ }^{19}$. Building on this work, we envisioned intercepting intermediates along the enantioselective cross-electrophile coupling reaction pathway with an olefin insertion step. Such a strategy could potentially lead to valuable enantioenriched olefin difunctionalization products.

Recently, nickel-catalyzed reductive alkene difunctionalization reactions have gained notoriety as one of the most efficient strategies to install vicinal bonds in a single operation. Relevant examples were reported by $\mathrm{Nevado}^{20,21}, \mathrm{Chu}^{22,23}, \mathrm{Martin}^{24}, \mathrm{Yuan}^{25}$ and Molander $^{26,27}$, among others. Impressive enantioselective threecomponent reactions were developed by $\mathrm{Diao}^{28}, \mathrm{Chu}^{29,30}, \mathrm{Nevado}^{31}$ as well as others ${ }^{32-38}$. In the final stages of preparing this manuscript, a complementary enantioselective three-component carboarylation of alkenes with alkyltrifluoroborates and aryl bromides was disclosed by Gutierrez and $\mathrm{Chu}^{29}$ (Fig. 1d). The redox-neutrality of this method is counterbalanced by the use of alkyltrifluoroborates, which must be prepared separately.

In this work, we present an example of enantioselective domino alky arylation of acrylates with alkyl- and aryl- bromides via cooperative nickel and photoredox catalysis (Fig. 1e). The organic photoredox 1,2,3,5-tetrakis(carbazol-9-yl)-4,6-dicyanobenzene (4CzIPN) acts as "pseudoreductant" with Hantzsch ester (HEH) as the terminal

a)

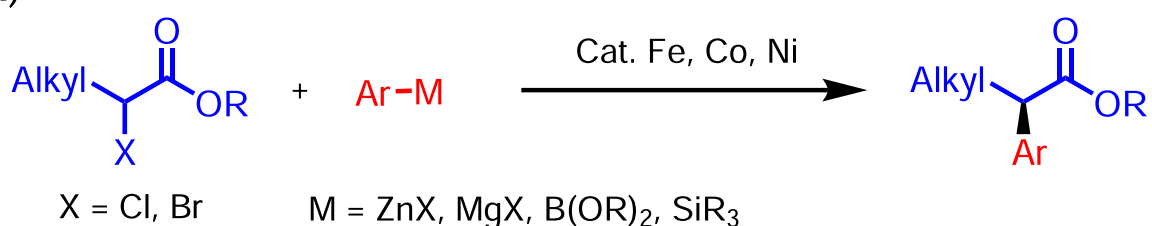

b)

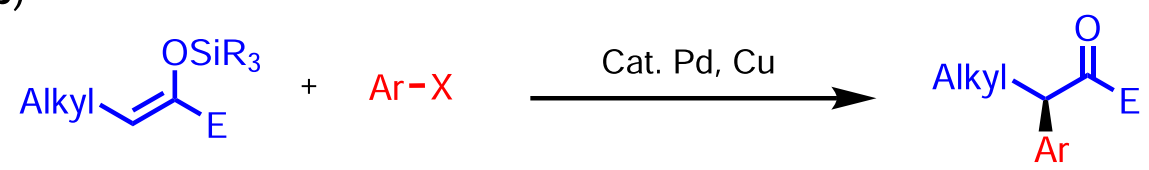

$\mathrm{E}=\mathrm{OR}, \mathrm{SR}, \mathrm{NR}_{2}, \quad \mathrm{X}=\mathrm{OTf}$, aryliodonium salt alkyl, aryl, etc.

c)

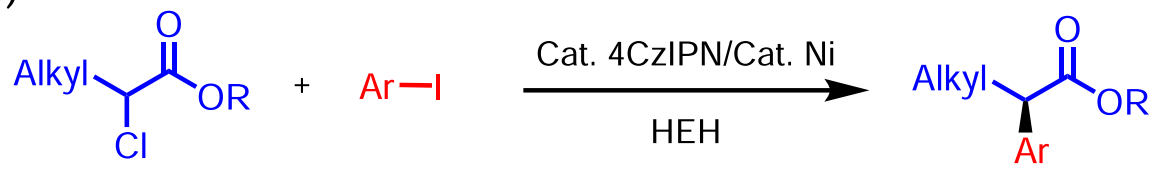

d)

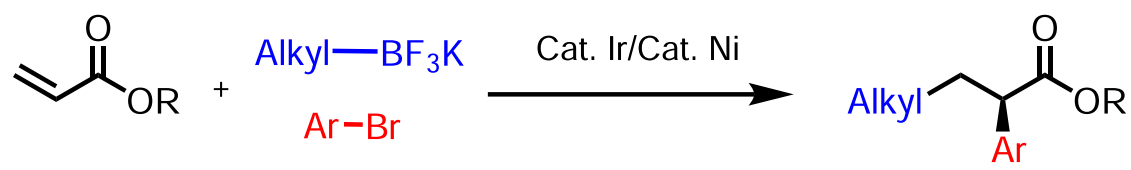

e) This work

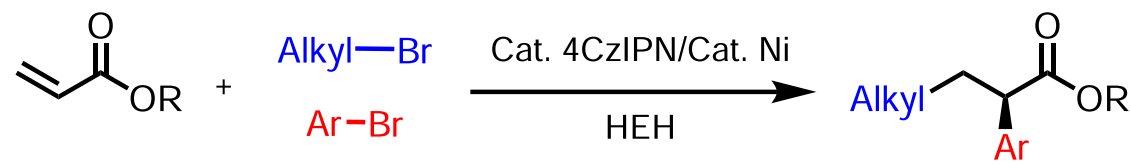

Fig. 1 Transition-metal-catalyzed asymmetric coupling reactions to synthesize NSAID derivatives. a The classical asymmetric cross-coupling with organometallic reagents. b Transition metal catalyzed asymmetric arylation of enol silane derivatives. c Nickel-photoredox co-catalyzed asymmetric reductive arylation of racemic $\alpha$-chloro esters. $\mathbf{d}$ A complementary photoredox/nickel catalyzed enantioselective carboarylation of alkenes. $\mathbf{e}$ This work: Nickel/photoredox catalyzed reductive asymmetric alky arylation of acrylates. 
Table 1 Optimization of reaction conditions [a].

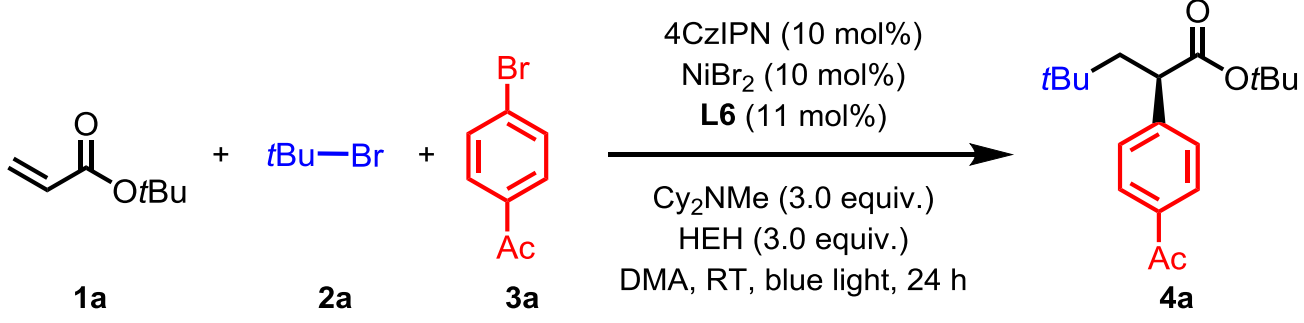

\begin{tabular}{|c|c|c|c|}
\hline entry & $\begin{array}{l}\text { Variations from standard } \\
\text { conditions }\end{array}$ & $\begin{array}{l}\text { Assay yield } \\
(\%)^{b}\end{array}$ & ee $(\%)^{\mathrm{c}}$ \\
\hline 1 & none & $82(79)^{\mathrm{d}}$ & 92 \\
\hline 2 & L1 instead of L6 & trace & -- \\
\hline 3 & L2 instead of L6 & 45 & 86 \\
\hline 4 & L3 instead of L6 & 38 & 85 \\
\hline 5 & L4 instead of L6 & 73 & 82 \\
\hline 6 & L5 instead of L6 & 77 & 89 \\
\hline 7 & No nickel salts & 0 & -- \\
\hline 8 & No 4CzIPN & 0 & -- \\
\hline 9 & No blue light & 0 & -- \\
\hline 10 & $\mathrm{No} \mathrm{Cy}_{2} \mathrm{NMe}$ & trace & -- \\
\hline 11 & No HEH & 32 & 92 \\
\hline 12 & $\mathrm{Zn}, \mathrm{Mn}$ or TDAE instead of $4 \mathrm{CzIPN} / \mathrm{HEH}$ & trace & -- \\
\hline
\end{tabular}

[a] Reactions conducted under Ar on $0.1 \mathrm{mmol}$ scale. [b] Determined by GC using tetradecane as an internal standard. [c] Determined by chiral HPLC on a CHIRALPAK IA column. [d] Isolated yield.

electron donor. The products of this cascade process are NSAID derivatives of potential use in medicinal chemistry.

\section{Results and discussion}

Reaction development and optimization. We began our investigation into the three-component olefin difunctionalization reaction by choosing tert-butyl acrylate (1a), tert-butyl bromide (2a) and 1-(4bromophenyl)ethan-1-one (3a) as model substrates (Table 1). After a systematic study of reaction conditions (see Table S1 in the Supporting Information for details), we were please to find that employing 4CzIPN (10 mol\%), $\mathrm{NiBr}_{2}$ (10 mol\%), L6 (11 mol\%), $\mathrm{Cy}_{2} \mathrm{NMe}$ (3.0 equiv.) and $\mathrm{HEH}$ (3.0 equiv.) in $\mathrm{N}, \mathrm{N}$-dimethylacetamide (DMA, $0.33 \mathrm{M}$ ) under blue LED irradiation at room temperature for $24 \mathrm{~h}$ furnished the $\alpha$-aryl ester (4a) in $82 \%$ assay yield (AY, determined by GC integration of the unpurified reaction mixture against an internal standard). Gratifyingly, the ee value of $4 \mathbf{a}$ was $92 \%$. The $(R)$ configuration of $\mathbf{4 a}$ was confirmed by comparison of its optical rotation with the literature value $e^{30}$ (see the Supporting Information for details). Based on our previous work ${ }^{19}$, enantioenriched bioxazoline ( $\mathrm{BiOX}$ ) frameworks were considered promising ligands for the three component coupling, giving up to $86 \%$ ee. (Table 1. entry 2-3). Further optimization, however, indicated the more electron-donating ${ }^{39}$ chiral biimidazoline (BiIM) ligands were better both in yield and enantioselectivity. Control experiments indicated that nickel salts, $4 \mathrm{CzIPN}, \mathrm{Cy}_{2} \mathrm{NMe}$ and blue LEDs are all crucial for the success of this transformation (Table 1. entry 7-10). Additionally, $\mathrm{HEH}$ played a key role in the reaction yields. Only $32 \%$ AY of $\mathbf{4 a}$ was detected in the absence of HEH (Table 1. entry 11), although, the enantioselectivity remained $92 \%$. In this case, it is possible that the $\mathrm{Cy}_{2} \mathrm{NMe}^{40-42}$ plays the role of reducing agent, albeit with much reduced efficiency. When other reductants, such as $\mathrm{Mn}$, $\mathrm{Zn}$ and tetrakis(dimethylamino)ethylene (TDAE) were employed, however, only trace products were detected. The diminished reactivity with $\mathrm{Mn}, \mathrm{Zn}$ and TDAE highlight the advantage of $\mathrm{HEH}$ under blue light in this process.

Substrate scope. With the optimized reaction conditions in hand, we next focused on the scope of the aryl bromide coupling partners using tert-butyl acrylate (1a) and 4-tert-butyl bromide 2a (Table 2). We were pleased to find that aryl bromides with functional groups in the 4-position, including electron-withdrawing groups (Ac, COOEt, $\left.\mathrm{CN}, \mathrm{CHO}, \mathrm{CF}_{3}, \mathrm{OCF}_{3}\right)$, halogens $(\mathrm{F}, \mathrm{Cl})$, neutral groups $(\mathrm{H}, \mathrm{Ph})$, and electron-donating groups $\left(t \mathrm{Bu}, \mathrm{OMe}, \mathrm{SMe}, \mathrm{NMe}_{2}\right)$ all exhibited high to excellent ee values (83-93\%) and moderate to good yields 
Table 2 Scope of aryl and (hetero)aryl bromides. ${ }^{[a]}$.
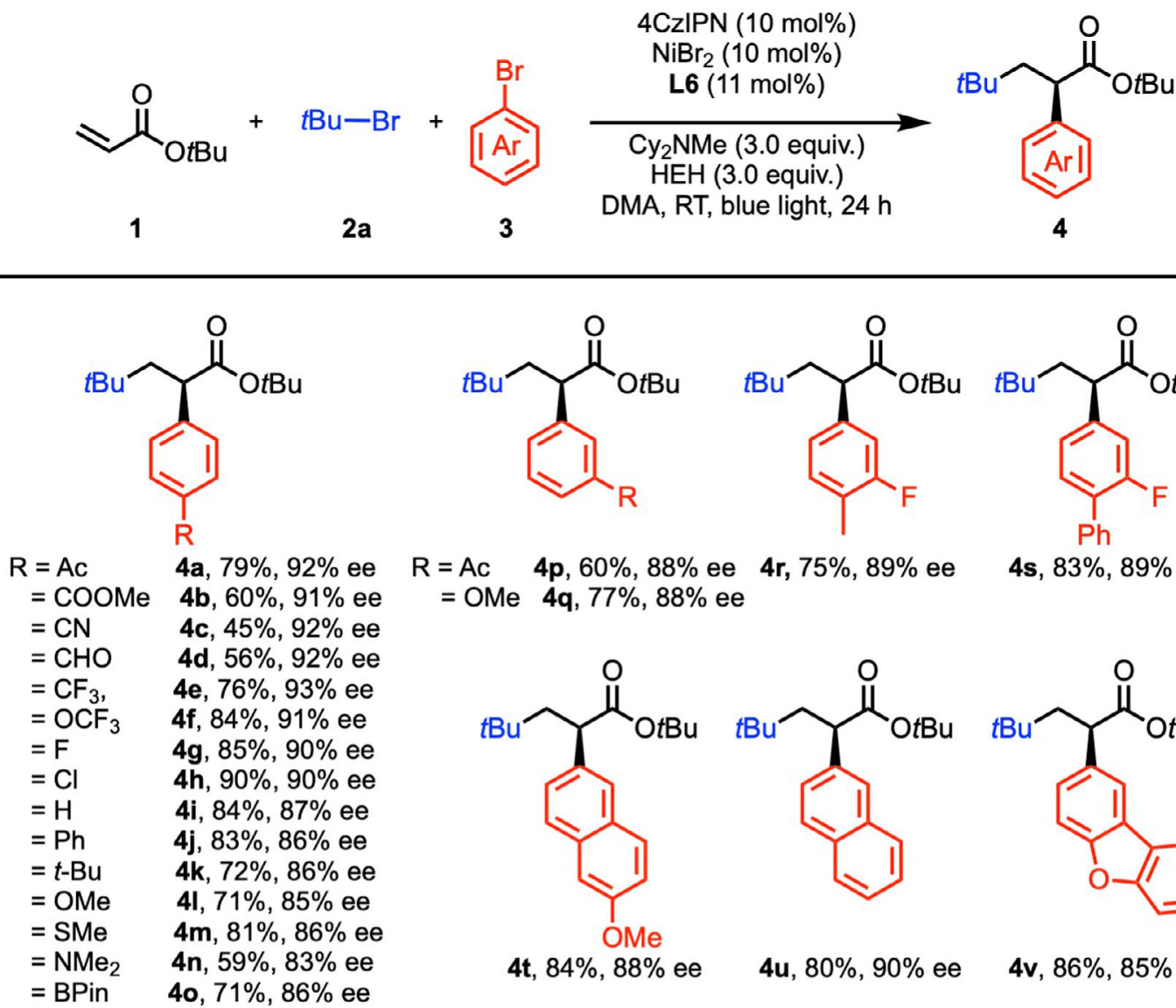<smiles>[R]c1cccc([C@@H](CC(C)(C)C)C(=O)OCCCC)c1</smiles>

$\mathrm{R}=\mathrm{Ac} \quad 4 \mathrm{p}, 60 \%, 88 \%$ ee $\quad \mathbf{4 r}, 75 \%, 89 \%$ ee $=$ OMe $4 q, 77 \%, 88 \%$ ee<smiles>CCCOC(=O)[C@H](CC(C)(C)C)c1ccc2cc(OC)ccc2c1</smiles><smiles>CCCCOC(=O)C(C)CCCC</smiles>

$4 u, 80 \%, 90 \%$ ee<smiles>CCCCOC(=O)[C@H](CC(C)C)c1ccc(-c2ccccc2)c(F)c1</smiles>

4s, $83 \%, 89 \%$ ee<smiles>CCCCOC(=O)[C@H](CC(C)(C)C)c1ccc2oc3ccccc3c2c1</smiles>

$4 \mathbf{v}, 86 \%, 85 \%$ ee<smiles>CCCCOC(=O)[C@@H](CC[13C](C)CC)c1ccc2c(c1)OCO2</smiles>

$4 w, 75 \%, 86 \%$ ee

$4 x, 75 \%, 89 \%$ ee

$4 y, 83 \%, 89 \%$ ee

$4 z, 82 \%, 88 \%$ ee

4aa, $75 \%, 83 \%$ ee<smiles>CCCCC[C@H](C(=O)OCCC)c1ccc2c(c1)c1ccccc1n2-c1ccccc1</smiles>

$4 a b, 86 \%, 86 \%$ ee<smiles>CCCCOC(=O)[C@H](CC(C)(C)C)c1ccc(COC(=O)[C@H](C)c2ccc(CC(C)C)cc2)cc1</smiles>

4ac, $82 \%, 87 \%$ de<smiles>CCCCC[C@H](C(=O)OCC)c1ccc(C(=O)OC/C=C(\C)CCC=C(C)C)cc1</smiles>

4ad, $79 \%, 91 \%$ ee

[a] All reactions conducted under Ar on $0.1 \mathrm{mmol}$ scale. Yield is that of the isolated product. The ee values were determined by chiral-phase HPLC.

(45-90\%). It is noteworthy that in prior studies, aryl bromides with electron-donating groups were poor substrates in reductive crosscoupling reactions ${ }^{43}$. Additionally, the 4-bromo phenyl BPin, which can be used for further transformations, was also well tolerated $(71 \%$ yield, $86 \%$ ee).
Aryl bromides bearing functional groups in the 3-position (Ac and $\mathrm{OMe})$ were fine substrates, furnishing the products $\mathbf{4 p}(60 \%$ yield, $88 \%$ ee) and $\mathbf{4 q}(77 \%$ yield, $88 \%$ ee), respectively. Disubstituted aryl bromides were good cross-coupling partners, affording products $\mathbf{4 r}$ with $89 \%$ ee and $75 \%$ yield. It is noteworthy 
that Flurbiprofen analog $4 \mathbf{s}$ and Naproxen analog 4t were obtained in good yields (83-84\%) with excellent enantioselectivities (88-89\%). Unfortunately, sterically hindered 2-substituted aryl bromides were not tolerated in this three-component asymmetric reductive cross-coupling (see Supporting Information for details).

Aryl bromides with extended $\pi$-systems, such as 2-bromonaphthylene, provided product $\mathbf{4 u}$ ( $80 \%$ yield, $90 \%$ ee). Heterocycles are important structural motifs in medicinal chemistry. Several aryl bromides containing heterocycles were, therefore, examined. 2Bromodibenzo $[b, d]$ furan, 5-bromo-2,3-dihydrobenzofuran, 5-bromobenzo $[d][1,3]$ dioxole, 5 -bromobenzofuran, 5-bromobenzo $[b]$ thiophene, 5-bromo-1-methyl- $1 \mathrm{H}$-indole and 3-bromo-9-phenyl-9Hcarbazole all exhibited good to excellent enantioselectivities (83-89\%) with good yields (75-86\%). To put the utility of this method to the test, ibuprofen and geraniol derivatives were subjected to the 3-component reaction. The desired products (4ac, 4ad) were generated in $79-82 \%$ yields and $87 \%$ de, $91 \%$ ee.

Table 3 Scope of $3^{\circ}$-alkyl bromides. ${ }^{[a]}$.

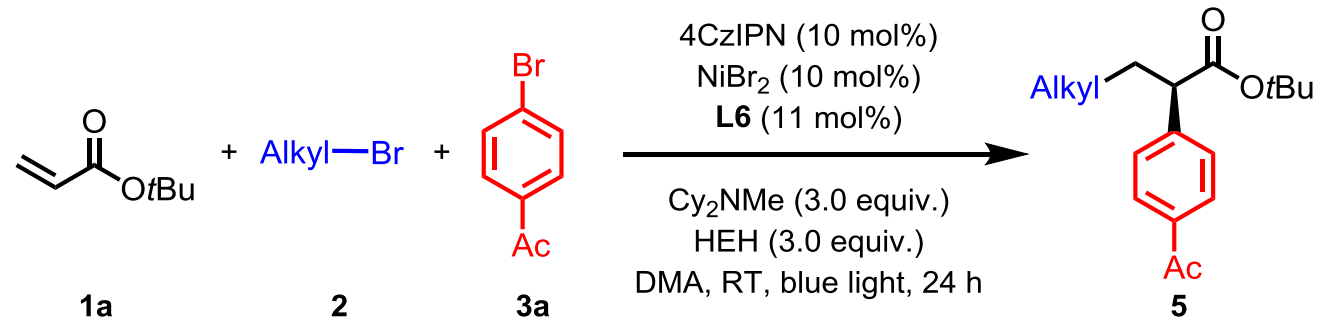<smiles>CCCCOC(=O)[C@H](CC(C)(C)CC)c1ccc(C)cc1</smiles>

5a, $75 \%, 92 \%$ ee<smiles>CCCCOC(=O)[C@H](CC(C)(C)CCBr)c1ccc(C(C)C)cc1</smiles>

5b, $70 \%, 85 \%$ ee<smiles>CCCCOC(=O)[C@H](CC(C)(C)CCc1ccccc1)c1ccc(C)cc1</smiles>

5c, $71 \%, 85 \%$ ee<smiles>CCCCOC(=O)[C@H](CC(C)(C)CCOC(=O)c1ccccc1)c1ccc(C(C)C)cc1</smiles>

5d, $79 \%, 83 \%$ ee<smiles>CCCCOC(=O)[C@H](CC(C)(C)CCOC(=O)c1ccc(C#N)cc1)c1ccc(C(C)(C)C)cc1</smiles>

5e, $72 \%, 83 \%$ ee<smiles>CCCCOC(=O)[C@H](CC(C)(C)CCOC(=O)c1ccncc1)c1ccc(C(C)(C)C)cc1</smiles>

5f, $60 \%, 85 \%$ ee<smiles>CCCCOC(=O)[C@H](CC(C)(C)CCOC(=O)c1cccs1)c1ccc(C(C)(C)C)cc1</smiles>

5 g, $72 \%, 83 \%$ ee<smiles>CCCCOC(=O)[C@H](CC(C)(C)CCOC(=O)c1ccco1)c1ccc(C(C)C)cc1</smiles>

5h, $80 \%, 83 \%$ ee<smiles>CCCCOC(=O)[C@H](CC(C)(C)CCOC(=O)CN1C(=O)c2ccccc2C1=O)c1ccc(C(C)(C)C)cc1</smiles>

5 i, $80 \%, 90 \%$ ee<smiles>CCCCOC(=O)[C@H](CC(C)(C)CCOC(=O)CCC(=O)c1ccccc1)c1ccc(C(C)C)cc1</smiles>

5j, $84 \%, 72 \%$ ee<smiles>CCCCOC(=O)[C@H](CC(C)(C)CCOC(=O)CC(c1ccccc1)c1ccccc1)c1ccc(C(C)C)cc1</smiles>

5k, $83 \%, 82 \%$ ee<smiles>CCCCC(C)(C)C[C@H](C(=O)OCCC)c1ccc(C(C)C)cc1</smiles>

$5 \mathrm{I}, 42 \%, 88 \%$ ee

[a] All reactions conducted under Ar on $0.1 \mathrm{mmol}$ scale. Yield is that of the isolated product. The ee values were determined by chiral-phase HPLC. 
To further explore the applications of this three-component asymmetric reductive cross-coupling method, we next examined the scope of the alkyl bromides (Table 3). Initially, acyclic tertiary alkyl bromides were examined. We were pleased to find that tertiary alkyl centers containing primary alkyl bromides, aryl, esters and ketone functional groups were compatible with the reaction conditions and afforded their corresponding products $(5 \mathbf{a}-\mathbf{5 k})$ in good to excellent yields $(60-84 \%)$ and good to excellent enantioselectivities (72-92\%). Another sterically hindered $3^{\circ}$ alkyl bromide, 1-bromo-1-methylcyclohexane, was also well-tolerated, furnishing the product $\mathbf{l}$ ( $42 \%$ yield, $88 \%$ ee). Use of $1^{\mathrm{O}}$ - or $2^{\mathrm{O}}$-alkylbromides gave rise to two-component aryl-alkyl cross coupling under these conditions ${ }^{44}$, because reactions of radicals derived from these species at the nickel center are competitive with radical addition to the unsaturated ester.

To push the system beyond $3^{\circ}$-alkylhalides, additional optimization (see Table S2 in the Supporting Information for details) was conducted. Gratifyingly, moderate changes (aryl and alkyl iodides instead of their corresponding bromides, $\mathrm{NiCl}_{2} \cdot$ glyme replacing $\mathrm{NiBr}_{2}$ and a mix solvent acetone/DMA $=2: 1$ replacing DMA) under otherwise standard conditions enabled coupling of less substituted alkyl radicals (Table 4 ). Not only $1^{\circ}$ alkyl halides (1-iodobutane) but also $2^{\circ}$-alkyl halides (2iodopropane, iodocyclopentane, iodocyclohexane, iodocycloheptane, iodocyclooctane) were tolerated, giving their corresponding products (6a-6f) in 15-75\% yield and 76-92\% ee. Other electrondeficient alkenes, such as $N$-phenylacrylamide, was tested under the standard conditions and afforded the product $\mathbf{6 g}$ (40\% yield, $33 \%$ ee). It is noteworthy that the electron-rich vinyl benzoate was also tolerated, albeit with diminished yield and ee (6h, 45\% yield, 50\% ee).

Mechanistic Studies. We desired to gain insight into the reaction pathway. Based on our previous work ${ }^{19}$, a detail analysis of the model reaction was conducted (Fig. 2a). The product 4a was isolated in $79 \%$ yield with $92 \%$ ee. The fate of the HEH was the

Table 4 Scope of $1^{\circ}$ and $2^{\circ}$-alkyl iodides and alkenes. ${ }^{[a]}$.

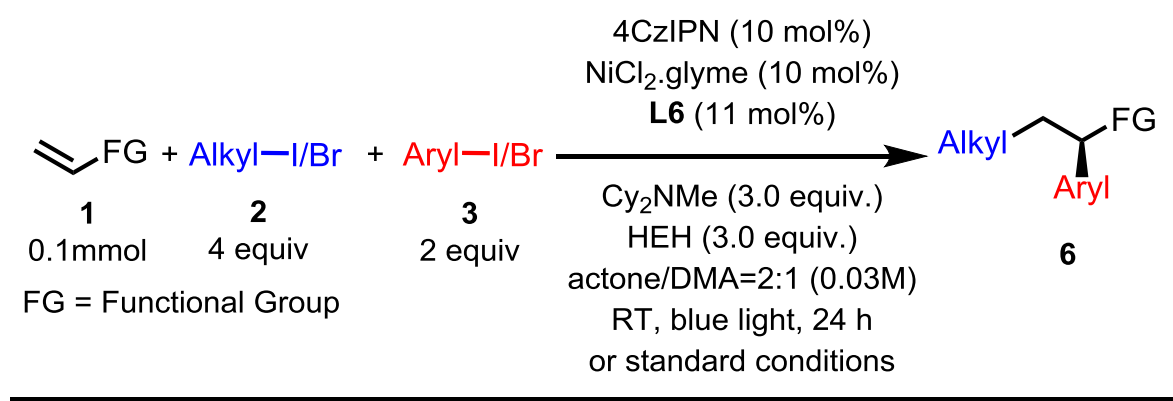<smiles>CCCCCC(C(=O)OCCC)c1ccc(C(C)(C)C)cc1</smiles>

6a, $15 \%, 76 \%$ ee<smiles>CCCCOC(=O)[C@H](CC1CCCCC1)c1ccc(C(C)C)cc1</smiles>

6d, $70 \%, 90 \%$ ee<smiles>CC(C)(C)C[C@H](C(=O)Nc1ccccc1)c1ccc(C(C)(C)C)cc1</smiles>

$6 g, 40 \%, 33 \%$ ee<smiles>CCCOC(=O)[C@H](CC(C)C)c1ccc(C(C)(C)C)cc1</smiles>

6b, $75 \%, 92 \%$ ee<smiles>CCCCOC(=O)[C@H](CC1CCCCCC1)c1ccc(C(C)C)cc1</smiles>

$6 e, 43 \%, 90 \%$ ee<smiles>CC(C)(C)C[C@H](OC(=O)c1ccccc1)c1ccc(C(C)(C)C)cc1</smiles>

$6 h, 45 \%, 50 \%$ ee<smiles>CCCCOC(=O)[C@H](CC1CCCC1)c1ccc(C(C)C)cc1</smiles>

6c, $68 \%, 90 \%$ ee<smiles>CCCCOC(=O)[C@H](CC1CCCCCCC1)c1ccc(C(C)(C)C)cc1</smiles>

6f, $50 \%, 90 \%$ ee

${ }^{[a]}$ All reactions conducted under Ar on $0.1 \mathrm{mmol}$ scale. Yield is that of the isolated product. The ee values were determined by chiral-phase HPLC. 


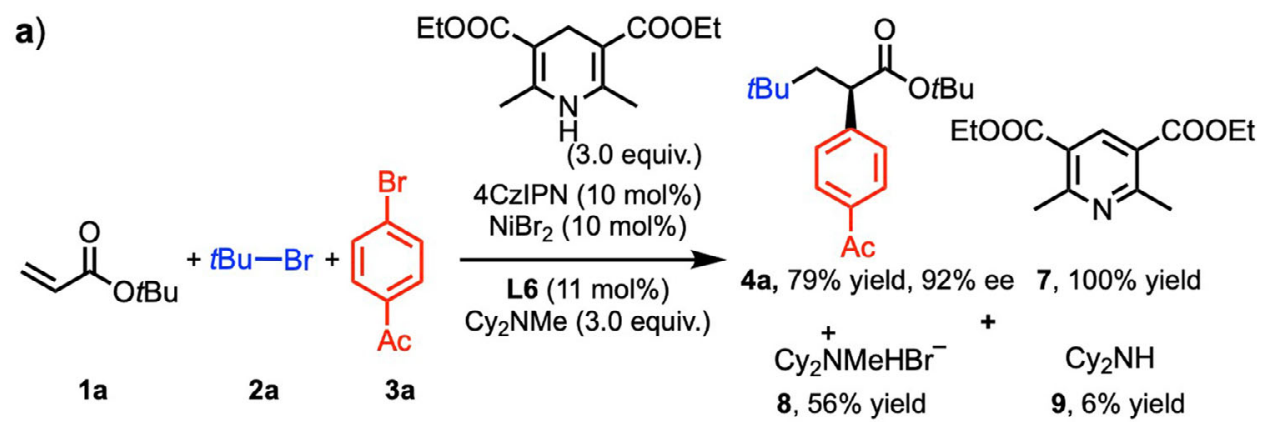

b)

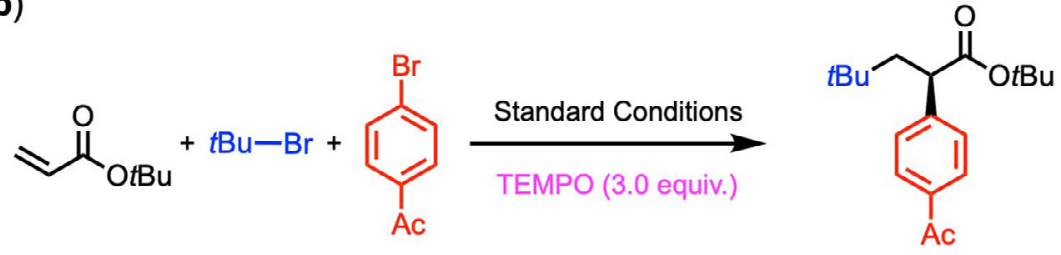

1a

$2 a$

3a

4a, not detected

c)<smiles>C=CC(=O)OCCCC(C)(C)Br</smiles>

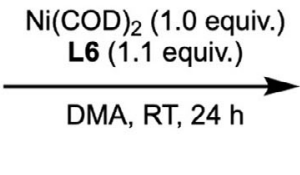<smiles>CCOC(=O)[C@H](CC(C)(C)C)c1ccc(C(C)(C)C)cc1</smiles>

$$
\text { 4a }
$$

Under blue light, $74 \%$ yield, $92 \%$ ee in the dark, $73 \%$ yield, $92 \%$ ee

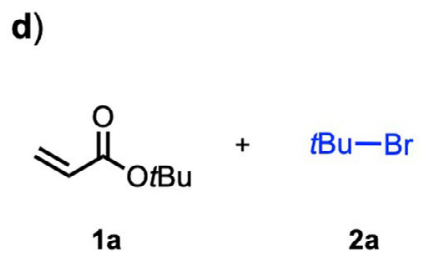

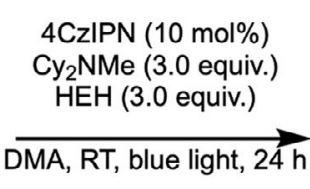

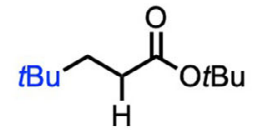

10, $70 \%$ GC-yield

Fig. 2 Mechanistic experiments. a Detail analysis of the model reaction. b Radical trapping reaction via TEMPO. c Stoichiometric studies. d Intermediate verification reaction.

expected pyridine (isolated in $100 \%$ yield relative to $\mathrm{HEH}$ ), derived from donation of 2 electrons and two protons. In the presence of $\mathrm{HEH}, \mathrm{Cy}_{2} \mathrm{NMe}$ most likely acted as a base, as determined by the isolation of $\mathrm{Cy}_{2} \mathrm{NMe} \cdot \mathrm{HBr}(8,56 \%$ yield). Only about $6 \%$ of the demethylated product, $\mathrm{Cy}_{2} \mathrm{NH}$, was detected after workup. The demethylated amine (9) likely arises from oxidation of the amine by ${ }^{*} 4 \mathrm{CzIPN}$ to the amine radical cation, loss of $\mathrm{H}^{\bullet}$ to generate the iminium ion, and hydrolysis by advantageous water during the reaction or upon workup ${ }^{40}$.

Additional experiments were then carried out to probe the reaction pathway. To explore the possibility of radical intermediates, the reaction was conducted under the standard conditions with the addition of the radical trap TEMPO. The presence of TEMPO shut down the formation of $\mathbf{4 a}$, consistent with the involvement of radicals (Fig. 2b).

Stoichiometric studies, wherein $\mathrm{NiBr}_{2}$ was replaced by 1.0 equiv $\mathrm{Ni}(\mathrm{COD})_{2}$ in the presence of 1.1 equiv $\mathbf{L 6}$ but in the absence of $4 \mathrm{CzIPN}, \mathrm{HEH}$ and $\mathrm{Cy}_{2} \mathrm{NMe}$ were carried out. This experiment was conducted both with and without blue light irradiation. With the light on $\mathbf{1}$ reacted with $\mathbf{2 a}$ and $\mathbf{3} \mathbf{a}$ to form cross-coupled product $\mathbf{4 a}$ (74\% yield, 92\% ee) (Fig. 2c). Likewise, when the reaction was conducted without irradiation, the cross-coupled product $\mathbf{4 a}$ was observed ( $73 \%$ yield, $92 \%$ ee). It is noteworthy that the ee of these stoichiometric reactions are identical to that observed under the standard catalytic conditions (Table 1, entry 1). These observations suggest that 1) the enantiodetermining step in the catalytic and stoichiometric reactions (Fig. 2b) are identical, and do not involve the photoredox cycle and 2) tert-butyl radical could be formed via SET reduction from the nickel catalyst (either $\mathrm{Ni}^{0}$ or $\mathrm{Ni}^{\mathrm{I}}$ ).

To probe the function of the photoredox cycle in this system, we performed the model reaction without $\mathrm{Ni} / \mathrm{L6}$ and bromobenzene (Fig. 2d). The radical addition/HAT quenching product (10) was obtained in $70 \% \mathrm{AY}$. This result indicates that in addition to reducing the $\mathrm{Ni}$ catalyst, the photoredox catalyst can undergo SET to the tert-butyl bromide to generate the tert-butyl radical. The radical then undergoes the Giese-type addition to the acrylate followed by abstraction of $\mathrm{H} \bullet$ from $\mathrm{HEH}$. Given that the olefin difunctionalization also proceeds via an $\alpha$-carbonyl radical, it must be that the $\alpha$-carbonyl radicals add to $\mathrm{L}^{*} \mathrm{Ni}(\mathrm{Ar}) \mathrm{Br}$ faster than they undergo HAT from HEH.

On the basis of related studies ${ }^{45}$, and the mechanistic experiments above, we present a proposed dual catalytic pathway for the enantioselective reductive three-component alkyl arylation reaction of alkenes with tertiary alkyl- and aryl-bromides (Fig. 3). The active $(\mathrm{BiIM}) \mathrm{Ni}^{0}\left[E 1 / 2^{\mathrm{red}}\left(\mathrm{Ni}^{\mathrm{II}} / \mathrm{Ni}^{0}\right)=-1.2 \mathrm{~V}\right.$ vs. $\left.\mathrm{SCE}\right]$ is generated in situ in two SET steps by the reduced photocatalyst 


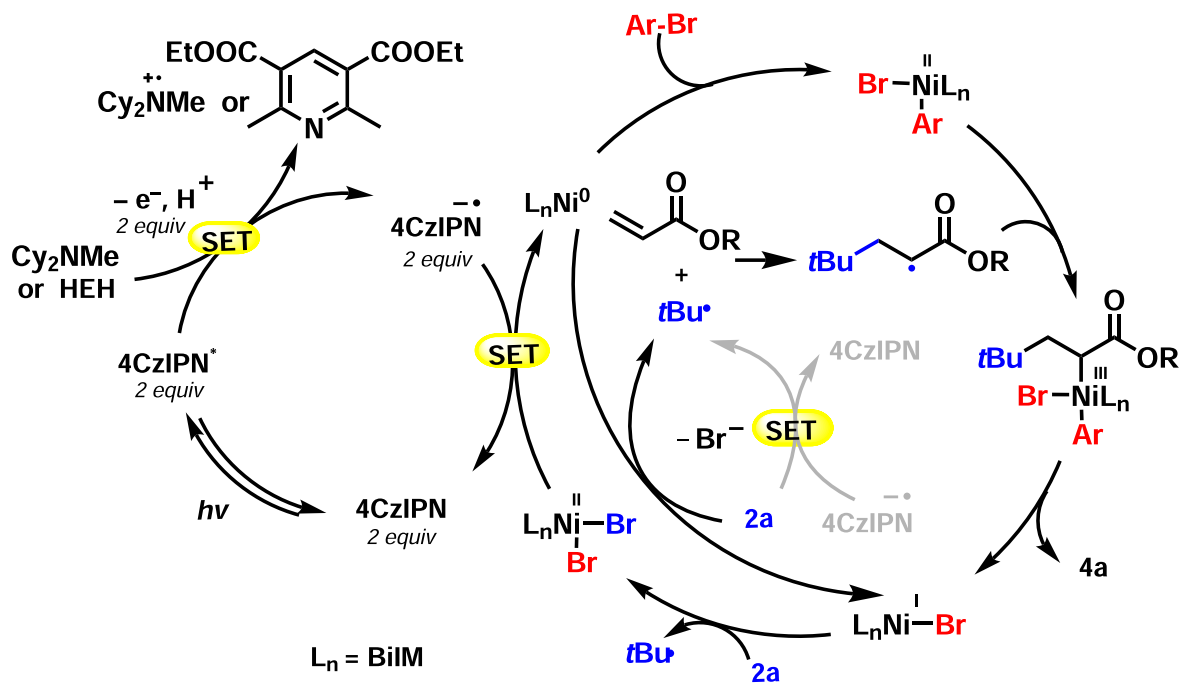

Fig. 3 Plausible catalytic reaction pathway. Key steps include oxidative addition of $\mathrm{Ar}-\mathrm{Br}$ to $\mathrm{Ni}(0)$, radical generation by SET from nickel to the alkyl bromide, Giese addition of the alkyl radical to the acrylate, trapping of the $\alpha$-carbonyl radical by Ni(II) to give Ni(III), which undergoes reductive elimination to give the product. The photocatalytic cycle involves reduction of $4 \mathrm{CZIPN}$ to $4 \mathrm{CZIPN}^{-}$, which is proposed to reduce the $\mathrm{Ni}$ catalyst to $\mathrm{Ni}(0)$.

$4 \mathrm{CzIPN}^{\bullet-}\left(E 1 / 2^{\text {red }}=-1.21 \mathrm{~V} \text { vs. } \mathrm{SCE}\right)^{46-49}$. The resulting (BiIM) $\mathrm{Ni}^{0}$ catalyst oxidatively adds the aryl bromide to give the (BiIM)Ni(Ar)Br complex ${ }^{50}$. The alkyl bromide undergoes SET by either the $\mathrm{Ni}$ or reduced $4 \mathrm{CzIPN}^{-}{ }^{-}$(as described above ${ }^{45}$ ) to generate the alkyl halide radical anion, which looses bromide to generate the tertiary radical. Addition of the tertiary radical to the acrylate forms the $\alpha$-carbonyl radical that is trapped by the (BiIM) Ni(Ar)Br complex to form the reactive $\mathrm{Ni}^{\mathrm{III}}$ species. The resulting $\mathrm{Ni}^{\mathrm{III}}$ intermediate $\mathrm{t}^{51}$ then undergoes rapid reductive elimination to give the product 4a. In the photoredox cycle, photoexcited ${ }^{*} 4 \mathrm{CzIPN}(\tau=5.1 \pm 0.5 \mu \mathrm{s})^{52}$ reacts with $\mathrm{HEH}$ to afford $4 \mathrm{CzIPN}^{\bullet-}$. The resulting $4 \mathrm{CzIPN}^{\bullet-}$ is oxidized by the nickel catalyst $\left(\mathrm{Ni}^{\mathrm{II}} / \mathrm{Ni}^{\mathrm{I}}\right)$ and/or $2 \mathbf{a}$ to regenerate $4 \mathrm{CzIPN}$.

In conclusion, we have developed an example of dual nickel/ organic photoredox catalyzed asymmetric reductive difunctionalization of acrylates with alkyl- and aryl-bromides to generate NSAID derivatives. The advantages of this reductive protocol are that it uses two bench stable and commercially available electrophiles and it is broadly tolerant of functional groups, avoids preformed moistureand/or air-sensitive organometallic reagents, and uses an organic reductant rather than the metal reductants used in most crosselectrophile coupling reactions.

\section{Methods}

General procedure 1. To an oven-dried vial equipped with a stir bar was added $\mathrm{NiBr}_{2}(2.2 \mathrm{mg}, 0.01 \mathrm{mmol}), \mathbf{L 6}(5.4 \mathrm{mg}, 0.011 \mathrm{mmol})$ and DMA $(3.0 \mathrm{~mL})$ under an argon atmosphere inside a glove box at RT to give a light green solution. After $30 \mathrm{~min}$ at RT, olefin $\left(0.1 \mathrm{mmol}, 1.0\right.$ equiv.), $3^{\circ}$-alkyl bromide $(0.4 \mathrm{mmol}, 4.0$ equiv. $)$ and aryl bromide $\left(0.2 \mathrm{mmol}, 2.0\right.$ equiv.) were added. Next, $\mathrm{Cy}_{2} \mathrm{NMe}(58.5 \mathrm{mg}$, $64 \mu \mathrm{L}, 0.3 \mathrm{mmol}, 3.0$ equiv.), $\mathrm{HEH}(75.9 \mathrm{mg}, 0.3 \mathrm{mmol}, 3.0$ equiv.) and $4 \mathrm{CzIPN}$ $(8.0 \mathrm{mg}, 0.01 \mathrm{mmol}$ ) were added. Once HEH and 4CzIPN were added, the solution turned from light green to yellow. The vial was sealed with a cap and removed from the glove box. The reaction mixture was stirred at RT under blue light. After $24 \mathrm{~h}$, the color of the reaction mixture changed back to light green. The vial was opened to air and EtOAc $(10 \mathrm{~mL})$ was added. The resulting solution was then washed with brine $(5 \mathrm{~mL} \times 5)$ and the organic layer separated and dried over anhydrous $\mathrm{Na}_{2} \mathrm{SO}_{4}$, filtered and concentrated to give the crude product. The crude residue was purified by flash column chromatography to afford the corresponding product.

General procedure 2. To an oven-dried vial equipped with a stir bar was added $\mathrm{NiCl}_{2}$ •glyme $(2.2 \mathrm{mg}, 0.01 \mathrm{mmol}), \mathbf{L} 6(5.4 \mathrm{mg}, 0.011 \mathrm{mmol})$ and acetone/DMA $(2.0 / 1.0$, $\mathrm{v} / \mathrm{v}, 3.0 \mathrm{~mL}$ ) under an argon atmosphere inside a glove box at RT, giving a light green solution. After $30 \mathrm{~min}$ at RT, tert-butyl acrylate $\left(0.1 \mathrm{mmol}, 1.0\right.$ equiv.), $1^{\circ}$ or $2^{\circ}$-alkyl iodides ( $0.4 \mathrm{mmol}, 4.0$ equiv.), 1-(4-iodophenyl)ethan-1-one ( $0.2 \mathrm{mmol}, 2.0$ equiv.), $\mathrm{Cy}_{2} \mathrm{NMe}(58.5 \mathrm{mg}, 64 \mu \mathrm{L}, 0.3 \mathrm{mmol}, 3.0$ equiv.), $\mathrm{HEH}(75.9 \mathrm{mg}, 0.3 \mathrm{mmol}, 3.0$ equiv.) and $4 \mathrm{CzIPN}(8.0 \mathrm{mg}, 0.01 \mathrm{mmol})$ were added. Once HEH and 4CzIPN were added, the solution turned from light green to yellow. The vial was sealed with a cap and removed from the glove box. The reaction mixture was stirred at RT under blue light. After $24 \mathrm{~h}$ the color of the solution changed back to light green. The vial was opened to air and EtOAc $(10 \mathrm{~mL})$ was added to the solution, which was then washed with brine $(5 \mathrm{~mL} \times 5)$. The organic layer was dried over anhydrous $\mathrm{Na}_{2} \mathrm{SO}_{4}$, filtered and concentrated to give the crude product. The crude residue was purified by flash column chromatography to afford the corresponding product.

\section{Data availability}

The detailed experimental procedures and characterization of compounds data generated in this study are provided in Supplementary Information. The authors declare that all other data supporting the findings of this study are available within the article and Supplementary Information files, and also are available from the corresponding author upon request.

Received: 12 January 2021; Accepted: 14 October 2021; Published online: 16 November 2021

\section{References}

1. Dhall, H., Kumar, A. \& Mishra, A. K. Synthesis of some novel substituted phenyl $\beta, \beta$-diphenyl propanoate with analgesic and anti-inflammatory activity. Curr. Bioact. Compd. 14, 26-32 (2018).

2. Landoni, M. F. \& Soraci, A. Pharmacology of chiral compounds: 2-arylpropionic acid derivatives. Curr. Drug Metab. 2, 37-51 (2001).

3. Pai, C.-C. et al. Highly effective chiral dipyridylphosphine ligands: synthesis, structural determination, and applications in the Ru-catalyzed asymmetric hydrogenation reactions. J. Am. Chem. Soc. 122, 11513-11514 (2000).

4. Li, J. et al. Asymmetric hydrogenation of $\alpha$-substituted acrylic acids catalyzed by a ruthenocenyl phosphino-oxazoline-ruthenium complex. Org. Lett. 18, 2122-2125 (2016)

5. Alper, H. \& Hamel, N. Asymmetric synthesis of acids by the palladium-catalyzed hydrocarboxylation of olefins in the presence of $(R)-(-)$ - or $(S)-(+)-1,1^{\prime}$-binaphthyl -2,2'-diyl hydrogen phosphate. J. Am. Chem. Soc. 112, 2803-2804 (1990).

6. Liu, F. et al. Cobalt-catalyzed enantioselective negishi cross-coupling of racemic $\alpha$-bromo esters with arylzincs. Chem. Eur. J. 24, 2059-2064 (2018).

7. Jin, M., Adak, L. \& Nakamura, M. Iron-catalyzed enantioselective crosscoupling reactions of $\alpha$-Chloroesters with aryl grignard reagents. J. Am. Chem. Soc. 137, 7128-7134 (2015).

8. Mao, J. et al. Cobalt-bisoxazoline-catalyzed asymmetric kumada crosscoupling of racemic $\alpha$-bromo esters with aryl grignard reagents. J. Am. Chem. Soc. 136, 17662-17668 (2014).

9. Dai, X., Strotman, N. A. \& Fu, G. C. Catalytic asymmetric hiyama cross-couplings of racemic a-bromo esters. J. Am. Chem. Soc. 130, 3302-3303 (2008).

10. Huang, Z., Liu, Z. \& Zhou Jianrong, S. An enantioselective, intermolecular $\alpha$ arylation of ester enolates to form tertiary stereocenters. J. Am. Chem. Soc. 133, 15882-15885 (2011).

11. Bigot, A., Williamson, A. E. \& Gaunt, M. J. Enantioselective $\alpha$-Arylation of $\mathrm{N}$-acyloxazolidinones with copper(II)-bisoxazoline catalysts and diaryliodonium salts. J. Am. Chem. Soc. 133, 13778-13781 (2011). 
12. Cherney, A. H., Kadunce, N. T. \& Reisman, S. E. Catalytic asymmetric reductive acyl cross-coupling: synthesis of enantioenriched acyclic $\alpha, \alpha$ disubstituted ketones. J. Am. Chem. Soc. 135, 7442-7445 (2013).

13. Cherney, A. H. \& Reisman, S. E. Nickel-catalyzed asymmetric reductive crosscoupling between vinyl and benzyl electrophiles. J. Am. Chem. Soc. 136, 14365-14368 (2014).

14. Hofstra, J. L., Cherney, A. H., Ordner, C. M. \& Reisman, S. E. Synthesis of enantioenriched allylic silanes via nickel-catalyzed reductive cross-coupling. J. Am. Chem. Soc. 140, 139-142 (2018).

15. Kadunce, N. T. \& Reisman, S. E. Nickel-catalyzed asymmetric reductive crosscoupling between heteroaryl iodides and $\alpha$-chloronitriles. J. Am. Chem. Soc. 137, 10480-10483 (2015).

16. Poremba, K. E., Kadunce, N. T., Suzuki, N., Cherney, A. H. \& Reisman, S. E. Nickel-catalyzed asymmetric reductive cross-coupling to access 1,1-diarylalkanes. J. Am. Chem. Soc. 139, 5684-5687 (2017).

17. Woods, B. P., Orlandi, M., Huang, C.-Y., Sigman, M. S. \& Doyle, A. G. Nickelcatalyzed enantioselective reductive cross-coupling of styrenyl aziridines. $J$. Am. Chem. Soc. 139, 5688-5691 (2017).

18. Zhao, Y. \& Weix, D. J. Enantioselective cross-coupling of meso-epoxides with aryl halides. J. Am. Chem. Soc. 137, 3237-3240 (2015).

19. Guan, H., Zhang, Q., Walsh, P. J. \& Mao, J. Nickel/Photoredox-Catalyzed Asymmetric Reductive Cross-Coupling of Racemic $\alpha$-chloro esters with aryl iodides. Angew. Chem. Int. Ed. 59, 5172-5177 (2020).

20. Garcia-Dominguez, A., Li, Z. \& Nevado, C. Nickel-catalyzed reductive dicarbofunctionalization of alkenes. J. Am. Chem. Soc. 139, 6835-6838 (2017).

21. Shu, W. et al. Ni-catalyzed reductive dicarbofunctionalization of nonactivated alkenes: scope and mechanistic insights. J. Am. Chem. Soc. 141, 13812-13821 (2019).

22. Zhao, X. et al. Intermolecular selective carboacylation of alkenes via nickelcatalyzed reductive radical relay. Nat. Commun. 9, 3488 (2018)

23. Guo, L., Tu, H.-Y., Zhu, S. \& Chu, L. Selective, intermolecular alkylarylation of alkenes via photoredox/nickel dual catalysis. Org. Lett. 21, 4771-4776 (2019).

24. Sun, S.-Z., Duan, Y., Mega, R. S., Somerville, R. J. \& Martin, R. Site-Selective 1,2-dicarbofunctionalization of vinyl boronates through dual catalysis. Angew. Chem. Int. Ed. 59, 4370-4374 (2020).

25. Zheng, S. et al. Selective 1,2-Aryl-aminoalkylation of alkenes enabled by metallaphotoredox catalysis. Angew. Chem. Int. Ed. 59, 17910-17916 (2020).

26. Badir, S. O. \& Molander, G. A. Developments in photoredox/nickel dualcatalyzed 1,2-Difunctionalizations. Chem 6, 1327-1339 (2020).

27. Campbell, M. W., Compton, J. S., Kelly, C. B. \& Molander, G. A. Threecomponent olefin dicarbofunctionalization enabled by nickel/photoredox dual catalysis. J. Am. Chem. Soc. 141, 20069-20078 (2019).

28. Anthony, D., Lin, Q., Baudet, J. \& Diao, T. Nickel-catalyzed asymmetric reductive diarylation of vinylarenes. Angew. Chem. Int. Ed. 58, 3198-3202 (2019).

29. Guo, L. et al. General method for enantioselective three-component carboarylation of alkenes enabled by visible-light dual photoredox/nickel catalysis. J. Am. Chem. Soc. 142, 20390-20399 (2020).

30. Tu, H.-Y. et al. Enantioselective three-component fluoroalkylarylation of unactivated olefins through nickel-catalyzed cross-electrophile coupling. J. Am. Chem. Soc. 142, 9604-9611 (2020).

31. Wei, X., Shu, W., Garcia-Dominguez, A., Merino, E. \& Nevado, C. Asymmetric Ni-catalyzed radical relayed reductive coupling. J. Am. Chem. Soc. 142, 13515-13522 (2020).

32. Wang, F., Chen, P. \& Liu, G. Copper-catalyzed radical relay for asymmetric radical transformations. Acc. Chem. Res. 51, 2036-2046 (2018).

33. Gu, Q.-S., Li, Z.-L. \& Liu, X.-Y. Copper(I)-catalyzed asymmetric reactions involving radicals. Acc. Chem. Res. 53, 170-18 (2020).

34. Jin, Y. \& Wang, C. Nickel-catalyzed asymmetric reductive arylalkylation of unactivated alkenes. Angew. Chem. Int. Ed. 58, 6722-6726 (2019).

35. Tian, Z.-X. et al. Highly enantioselective cross-electrophile aryl-alkenylation of unactivated alkenes. J. Am. Chem. Soc. 141, 7637-7643 (2019).

36. Wang, K., Ding, Z., Zhou, Z. \& Kong, W. Ni-catalyzed enantioselective reductive diarylation of activated alkenes by domino cyclization/crosscoupling. J. Am. Chem. Soc. 140, 12364-12368 (2018).

37. He, J. et al. Nickel-catalyzed asymmetric reductive 1,2-carboamination of unactivated alkenes. Angew. Chem. Int. Ed. 59, 2328-2332 (2020).

38. Wang, W., Ding, C. \& Yin, G. Catalyst-controlled enantioselective 1,1arylboration of unactivated olefins. Nat. Catal. 3, 951-958 (2020).

39. Cheng, X., Lu, H. \& Lu, Z. Enantioselective benzylic C-H arylation via photoredox and nickel dual catalysis. Nat. Commun. 10, 3549 (2019).

40. Fan, X., Gong, X., Ma, M., Wang, R. \& Walsh, P. J. Visible light-promoted $\mathrm{CO}_{2}$ fixation with imines to synthesize diaryl $\alpha$-amino acids. Nat. Commun. 9, 4936 (2018).

41. Wang, R., Ma, M., Gong, X., Fan, X. \& Walsh, P. J. Reductive cross-coupling of aldehydes and imines mediated by visible light photoredox catalysis. Org. Lett. 21, 23-27 (2019).
42. Wang, R. et al. Visible-light-mediated umpolung reactivity of imines: ketimine reductions with Cy2NMe and water. Org. Lett. 20, 2433-2436 (2018).

43. Lucas, E. L. \& Jarvo, E. R. Stereospecific and stereoconvergent cross-couplings between alkyl electrophiles. Nat. Rev. Chem. 1, 0065 (2017).

44. Duan, Z., Li, W. \& Lei, A. Nickel-catalyzed reductive cross-coupling of aryl bromides with alkyl bromides: $\mathrm{Et}_{3} \mathrm{~N}$ as the terminal reductant. Org. Lett. 18 4012-4015 (2016)

45. Neumann, M., Fueldner, S., Koenig, B. \& Zeitler, K. Metal-free, cooperative asymmetric organophotoredox catalysis with visible light. Angew. Chem. Int. Ed. 50, 951-954 (2011).

46. Tellis, J. C., Primer, D. N. \& Molander, G. A. Single-electron transmetalation in organoboron cross-coupling by photoredox/nickel dual catalysis. Science 345, 433-436 (2014).

47. Zuo, Z. et al. Enantioselective decarboxylative arylation of $\alpha$-amino acids via the merger of photoredox and nickel catalysis. J. Am. Chem. Soc. 138, 1832-1835 (2016)

48. Zuo, Z. et al. Merging photoredox with nickel catalysis: coupling of $\alpha$-carboxyl $\mathrm{sp}_{3}$-carbons with aryl halides. Science 345, 437-440 (2014).

49. Meng, Q.-Y., Wang, S., Huff, G. S. \& Koenig, B. Ligand-controlled regioselective hydrocarboxylation of styrenes with $\mathrm{CO}_{2}$ by combining visible light and nickel catalysis. J. Am. Chem. Soc. 140, 3198-3201 (2018).

50. Weix, D. J. Methods and mechanisms for cross-electrophile coupling of $\mathrm{Csp}_{2}$ halides with alkyl electrophiles. Acc. Chem. Res. 48, 1767-1775 (2015).

51. Fu, G. C. Transition-metal catalysis of nucleophilic substitution reactions: a radical alternative to $\mathrm{SN}_{1}$ and $\mathrm{SN}_{2}$ processes. ACS Cent. Sci. 3, 692-700 (2017).

52. Uoyama, H., Goushi, K., Shizu, K., Nomura, H. \& Adachi, C. Highly efficient organic light-emitting diodes from delayed fluorescence. Nature 492, 234-238 (2012).

\section{Acknowledgements}

We acknowledge the National Natural Science Foundation of China (22071107 and 21801128 to J.M.), Natural Science Foundation of Jiangsu Province, China (BK20170965 to J.M.), and Nanjing Tech University (BK20211588 and 39837112) for financial support. P.J.W. thanks the US National Science Foundation (CHE-1902509).

\section{Author contributions}

P.Q. and H.G. are contributed equally to this work and mechanistic study with the help of Y.W., Q.L., F.Z. and D.X. The project was conceived by J.M. and P.Q. with help from P.J.W The project was directed by J.M. and the manuscript was written by H.G., J.M. and P.J.W.

\section{Competing interests}

The authors declare no competing interests.

\section{Additional information}

Supplementary information The online version contains supplementary material available at https://doi.org/10.1038/s41467-021-26794-8.

Correspondence and requests for materials should be addressed to Patrick J. Walsh or Jianyou Mao.

Peer review information Nature Communications thanks the anonymous reviewer(s) for their contribution to the peer review of this work. Peer reviewer reports are available.

Reprints and permission information is available at http://www.nature.com/reprints

Publisher's note Springer Nature remains neutral with regard to jurisdictional claims in published maps and institutional affiliations.

(i)

Open Access This article is licensed under a Creative Commons Attribution 4.0 International License, which permits use, sharing, adaptation, distribution and reproduction in any medium or format, as long as you give appropriate credit to the original author(s) and the source, provide a link to the Creative Commons license, and indicate if changes were made. The images or other third party material in this article are included in the article's Creative Commons license, unless indicated otherwise in a credit line to the material. If material is not included in the article's Creative Commons license and your intended use is not permitted by statutory regulation or exceeds the permitted use, you will need to obtain permission directly from the copyright holder. To view a copy of this license, visit http://creativecommons.org/ licenses/by/4.0/.

(C) The Author(s) 2021 